\title{
Ferroelectric polymer scaffolds based on a copolymer of tetrafluoroethylene with vinylidene fluoride: fabrication and properties
}

\author{
E.N. Bolbasov ${ }^{\mathrm{a}}$, Y.G. Anissimov ${ }^{\mathrm{b}}$, A.V. Pustovoytov ${ }^{\mathrm{a}}$, I.A. Khlusov ${ }^{\mathrm{a}, \mathrm{c}}$, \\ A.A. Zaitsev ${ }^{\mathrm{c}}$, K.V. Zaitsev ${ }^{\mathrm{c}}$, I.N. Lapin ${ }^{\mathrm{d}}$, S.I. Tverdokhlebov ${ }^{\mathrm{a}}$
}

a) Tomsk Polytechnic University, 634050, 30, Lenin Avenue, Tomsk, Russia

b) Griffith University, School of Biomolecular and Physical Sciences, Brisbane, QLD, Australia

c) Tomsk Scientific research Institute of Balneology and Physiotherapy, Tomsk; Russia

d) Tomsk State University, 634050, 36, Lenin Avenue, Tomsk, Russia

Corresponding author: Sergei I. Tverdokhlebov, e-mail: tverd@tpu.ru, phone: +7(3822)5634-37, address: 40A-2, Istochnaya st., Tomsk, Russia, 634050.

E.N. Bolbasov, e-mail: ebolbasov@gmail.com, phone: +7(3822)56-34-37, address: 45A-49, Melnichnaya st., Tomsk, Russia, 634050.

Y.G. Anissimov, e-mail: Y.Anissimov@Griffith.edu.au; address: School of Biomolecular and Physical Sciences, Gold Coast campus, Griffith University, QLD 4222, Australia.

A.V. Pustovoytov, e-mail: andrius_222@mail.ru, phone: +7(3822)56-34-37, address: 30, Lenin av., Tomsk, Russia, 634050.

A.A. Zaitsev, e-mail: prim@niikf.tomsk.ru, phone: +7(3822)51-20-05, address: 1, R. Luksemburg st., Tomsk, Russia, 634050.

K.V. Zaitsev, e-mail: zaitsev-kv@mail.ru, +7(3822)51-20-05, address: 1, R. Luksemburg st., Tomsk, Russia, 634050.

I.A. Khlusov, e-mail: khlusov63@mail.ru, address: 31-319, Sibirskaya st., Tomsk, Russia, 634050 .

I.N. Lapin, e-mail: 201kiop@mail.ru, address: 45A-50, Melnichnaya st., Tomsk, Russia, 634050 .

\begin{abstract}
.
A solution blow spinning technique is a method developed recently for making nonwoven webs of micro- and nanofibres. The principle advantage of this method compared to a more traditional electrospinning process is that it has significantly higher production rate. In this work solution blow spinning method was further developed to produce nonwoven polymeric scaffolds based on a copolymer of tetrafluoroethylene with vinylidene fluoride solution in acetone. A crucial feature
\end{abstract}


of the proposed method is that no use of high-voltage equipment is required, which further improves the method's economics. Scanning electron microscopy analysis of the samples demonstrated that the surface morphology of the nonwoven materials is dependent on the polymer concentration in the spinning solution. It was concluded that an optimum morphology of the nonwoven scaffolds for medical applications is achieved by using $5 \%$ solution of the copolymer. It was established that the scaffolds produced from the $5 \%$ solution have a fractal structure and anisotropic mechanical properties. X-ray diffraction, infrared spectroscopy, Raman spectroscopy and differential scanning calorimetry demonstrated that the fabricated nonwoven material have crystal structure that exhibits ferroelectric properties. Gas chromatography has shown that the amount of acetone in the nonwoven material does not exceed the maximum allowable concentration of $0.5 \%$. In vitro analysis, using the culture of motile cells, confirmed that the nonwoven material is non-toxic and does not alter the morpho-functional status of stem cells for short-term cultivation, and therefore can potentially be used in medical applications.

Keywords: copolymer of tetrafluoroethylene with vinylidene fluoride, polymeric ferroelectrics, solution blow spinning, scaffolds, bovine semen, cytotoxicity, human stromal cells, morphofunctional status.

\section{Abbreviations}

ACP - acid phosphatase, ALP - alkaline phosphatase, DSC - differential scanning calorimetry, EDX - energy dispersive spectroscopy analysis, FTIR - Fourier transform infrared spectroscopy, GC - gas chromatography, HLPSC - human lung prenatal stromal cells, SBS - solution blow spinning, SEM - scanning electron microscopy, VDF-TeFE - tetrafluoroethylene copolymer with vinylidene fluoride, XRD - X-ray diffraction.

\section{Highlights}

- Using the method of solution blow spinning nonwoven material based on tetrafluoroethylene copolymer with vinylidene fluoride was fabricated.

- Scanning electron microscopy of the nonwoven material demonstrated that it has complex spatial organization and high porosity.

- X-ray diffraction, infrared spectroscopy, Raman spectroscopy and differential scanning calorimetry established that the fabricated nonwoven material exhibits ferroelectric properties.

- GC established that the content of residual solvent (acetone) in the nonwoven material does not exceed $0.5 \%$ wt. 
- Using motile cells of bovine semen in vitro it was demonstrated that the resulting material is non-toxic.

- Using the culture of human fibroblast-like cells it was demonstrated that the material does not affect cells’ morpho-functional status in short-term cultivation in vitro.

\section{Introduction}

Fluorocarbon plastics are widely used in modern medicine. Examples include implantable products that are manufactured using fluorocarbon plastics and used successfully in various areas of medicine: coverage of defects of the cornea [1], prosthetic blood vessels [2-3], plastic walls of abdominal hernia [4], thromboresistive coatings of coronary stents [5-6] and bone regeneration in orthopedic and trauma treatments [7-10]. Some fluorocarbon plastics, for example, polyvinylidenefluoride, VDF-TeFE and polyvinylidenefluoride-co-trifluoroethylene have ferroelectric properties [11-12]. Ferroelectric polymer materials can change their surface charge, thus actively influencing (affecting) the cellular pool that is placed on the surface of such materials [13-14].

Three-dimensional polymer structures, the so-called scaffolds, with the ferroelectric properties can stimulate attachment and proliferation of neural cells and potentially can be used for the regeneration of damaged nerves [15-16].

An electrospinning method is the most common way to create solid polymer scaffolds from polymer solutions. The method involves application of high DC voltages of the order of 10 to 20 $\mathrm{kV}$ to the polymer solution exiting from fine nozzles under the influence of gravity or mechanical pressure. When the electric field force exceeds the surface tension of the polymer solution thin jets of the solution are produced that, combined with a rapid evaporation of the solvent from jets, leads to the formation of nanofibres [17-18]. Scaffolds obtained by the electrospinning method have narrow distribution of the fibre diameter, high strength and biocompatibility properties [19].

However the electrospinning method has limitations, such as the selectivity of the method to the dielectric constant of the solvent used for producing the spinning solution [20]. An alternative way of making scaffolds is the method proposed by Medeiros et al., called "solution blow spinning" (SBS), where high-velocity gas flow is used as the fibre-forming driving force [21-22]. 
Compared to the electrospinning, SBS method does not impose restrictions on the dielectric constant of the solvent or require the use of high-voltage equipment. SBS method also allows simultaneous use of multiple nozzles, which provides high productivity of the scaffold fabrication. The main units of the installation that implements the method of SBS (Fig. $1 \mathrm{a}, \mathrm{b}$ ) are concentric spray nozzle and dispensing system, which is necessary to control the amount of the polymer solution delivered to the nozzle. Under the action of compressed air at the outlet of the nozzle the nonwoven material consisting of interlaced polymeric fibres is formed at the collector. The method had been implemented for different polymeric materials and various types of spray systems [23-25].

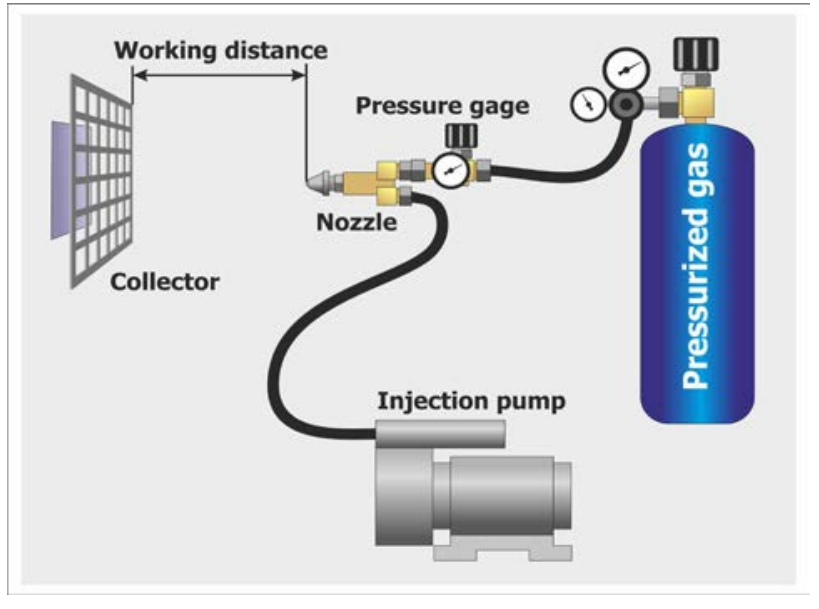

$\mathrm{a}$

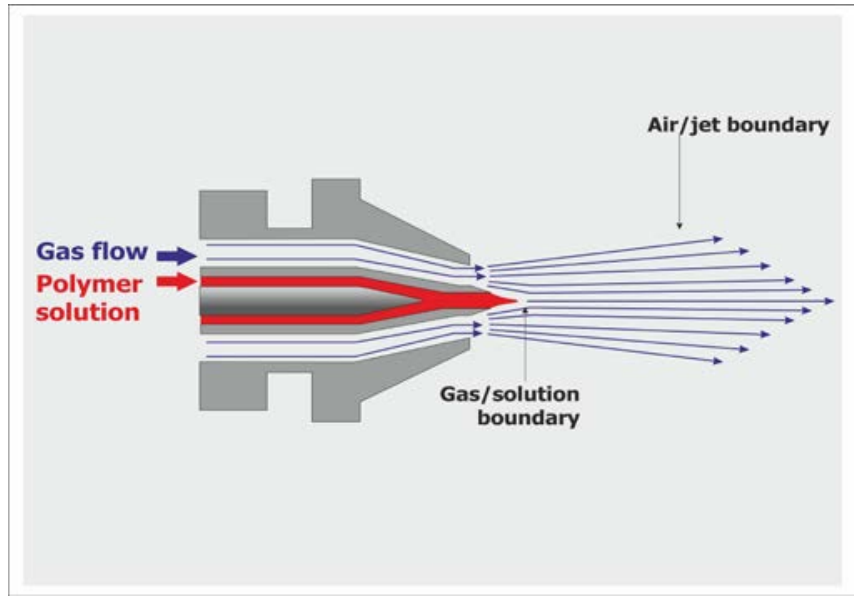

$\mathrm{b}$

Fig. 1. General setup (a) and a diagram of the spray nozzle unit (b) for the formation of nonwoven materials by solution blow spinning.

Copolymer VDF-TeFE has ferromagnetic and piezoelectric properties, high chemical resistance, good mechanical properties and ability to dissolve in organic solvents with low toxicity, such as acetone, methyl ethyl ketone, butyl acetate and ethyl acetate [26-27]. In this work the SBS installation was designed, manufactured and used to fabricate the polymeric nonwoven material based on the copolymer VDF-TeFE. It is known that the processing conditions of copolymer VDF-TeFE, such as the rate of crystallization from the melt or solution, orientational stretching, annealing, hardening, etc. have a significant effect on the conformation of the polymer chains and, consequently, determine various physical characteristics of the formed materials [28]. Therefore in this work study of the mechanical properties, morphology of the surface, the crystal structure and the chemical composition of the nonwoven material were conducted. The 
cytotoxicity of the material and its influence on the morpho-functional status of stromal cells was also investigated.

\section{Materials and methods}

\subsection{Preparation of nonwoven material}

The key parameters for the SBS method such as the compressed gas pressure and the flow rate of the polymer solution were chosen by analyzing the work of Oliveira et al. [29] and were 3.5 bar and $25 \mu \mathrm{l} / \mathrm{min}$ respectively. Oliveira et al. [29] demonstrated that these parameters produce nonwoven materials with a spatial structure close to those produced using electrospinning method. Other important parameters are nozzles diameters for supplying a polymer solution $(0.35 \mathrm{~mm})$ and compressed air $(0.53 \mathrm{~mm})$ as well as the distance from the nozzle to the collector (400 mm). Various solution concentrations of a random copolymer of VDF-TeFE (TeFE containing 20 mol\%, HaloPolymer, Russia) in acetone (Merck) of 3, 5, 7, and 9\% were used for the fabrication of nonwoven materials. Preparation of the solution of the copolymer VDF-TeFE was carried out in a sealed glass reactor at a temperature of $50{ }^{\circ} \mathrm{C}$ and continuous stirring until a homogeneous clear solution was achieved. The resulting solution was cooled to room temperature.

Nonwoven materials were fabricated as mats with the linear dimensions of $300 \times 200 \mathrm{~mm}$ and the thickness of $200 \pm 10 \mu \mathrm{m}$. The samples were cut from the nonwoven material at a distance of at least $50 \mathrm{~mm}$ from the edge. Samples of the material were incubated in a vacuum chamber with a residual pressure of $5 \times 10^{-5}$ Pa for 48 hours to remove residual acetone.

The powder samples of the copolymer VDF-TeFE unexposed to organic solvents were used as a control. Control samples were incubated in the same conditions as the nonwoven material before investigations. Samples of the nonwoven material were sterilized in ethylene oxide (Anprolene AN4000, Andersen Sterilizers, Inc.) for biological research.

\subsection{The study of the surface morphology, porosity and EDX}

The nonwoven material's surface morphology was determined by scanning electron microscopy (SEM, ESEM Quanta 400 FEG) without applying conductive coatings in a low vacuum in an atmosphere of water vapour. During scanning the residual pressure in the chamber, an accelerating voltage and beam current was $60 \mathrm{~Pa}, 20 \mathrm{kV}$ and $5 \mu \mathrm{A}$ respectively. Morphological 
characteristics of the nonwoven material (pore size, fibre diameter and the size of particles) were measured using the software Image J 1.38 (National Institutes of Health, USA). A preliminary study of the chemical composition of the nonwoven material was performed using energy dispersive spectroscopy analysis (EDX, Genesis 4000 system with S-UTW-Si (Li) detector). Analysis of the semi-quantitative chemical composition of scaffolds was carried out by the method of three corrections: in the average atomic number, absorption and fluorescence.

Nonwoven material's porosity was determined as in the method described in [15], using equation:

$$
P=\left(1-\rho_{\text {NM }} / \rho_{\text {Powder }}\right) \times 100 \%
$$

where $P$ is the porosity of the nonwoven material (\%), $\rho_{N M}$ is the density of the nonwoven material and $\rho_{\text {Powder }}$ is the density of the raw powder of VDF-TeFE.

The density of the powder $\rho_{\text {Powder }}$ and the nonwoven material $\rho_{N M}$ were measured as the ratio of the sample weight to its volume. The mass of the samples was determined using the analytical balance (GOSMETR, Russia). Measurement of the volume of samples was performed using a pycnometer ATC (Thermo Scientific, USA).

\subsection{Mechanical properties}

Mechanical properties of the nonwoven material were investigated using the recommendations of ISO 9073.3:1989. The test samples were cut from the original nonwoven mats in the form of stripes of $20 \times 80 \mathrm{~mm}$ so that the $80 \mathrm{~mm}$ edge was parallel (the samples of the first group) or perpendicular (samples of the second group) to the $300 \mathrm{~mm}$ edge of the original mat. 5 samples of each type were prepared. The study was conducted using Instron 5948 (ultra-high precision system for mechanical testing) with the width of the working area of $50 \mathrm{~mm}$ and the pre-load force on the sample of $0.15 \mathrm{~N}$. Sandpaper with the grit of P280 was glued to the testing machine’s clamping jaws to prevent the slippage of samples in accordance with ISO-6344.

\subsection{X-ray diffraction analysis}

Investigations of the crystal structure of the samples were conducted by X-ray diffraction analysis using a Shimadzu XRD 6000 diffractometer. The samples were irradiated with monochromatic $\mathrm{Cu}$ K-alpha radiation with a wavelength of $1.54056 \AA$ and using the following parameters: the accelerating voltage of $40 \mathrm{kV}$, the beam current of $30 \mathrm{~mA}$, the scanning angle 
range $10-20^{\circ}$, scanning step size $0.0200^{\circ}$ and signal collection time of 1.5 seconds. The degree of crystallinity of the samples was calculated using the software package Shimadzu 6000/7000 v 1.52. The average size of the crystals $\left(l_{c}\right)$ of the samples was calculated using Debye-Scherrer equation:

$$
l_{c}=\frac{k \lambda}{\cos \theta \sqrt{\beta^{2}-\beta_{r}^{2}}}
$$

where $\lambda$ is the wavelength of the incident radiation, $\beta$ the width of the reflection at half height, $\beta_{r}$ - apparatus' broadening reflex, $\theta$ - angle of diffraction and $k=0.9$.

\subsection{Thermal analysis}

\subsubsection{TGA analysis}

The study of the thermal stability of the samples was carried out by thermogravimetric analysis (TGA). The initial decomposition temperature of the sample $\left(T_{\mathrm{A}}\right)$, the temperature of halfdecomposition $\left(T_{\mathrm{C}}\right)$ and the temperature of complete decomposition $\left(T_{\mathrm{B}}\right)$ were determined. Studies were carried out using the combined TGA/DSC analyzer SDT Q600 (TA Instruments) according to ISO 11358 in a dry air atmosphere using the heating rate of $10{ }^{\circ} \mathrm{C} / \mathrm{min}$, temperature range $30{ }^{\circ} \mathrm{C}$ to $600{ }^{\circ} \mathrm{C}$ and air flow of $100.0 \mathrm{ml} / \mathrm{min}$.

\subsubsection{DSC analysis}

Differential scanning calorimetry (DSC) was used to determine the melting point $\left(T_{m}\right)$, the heat of fusion $\left(\Delta H_{g}\right)$ and the change in the degree of crystallinity $\Delta X_{c}(\%)$.The studies were conducted on the differential scanning calorimeter DSC Q2000 (TA Instruments) in a dry air atmosphere using the heating rate of $10{ }^{\circ} \mathrm{C} / \mathrm{min}$, temperature range $60{ }^{\circ} \mathrm{C}$ to $200{ }^{\circ} \mathrm{C}$ and air flow of 50.0 $\mathrm{ml} / \mathrm{min}$.

The change in the degree of crystallinity $\Delta X_{c}$ (\%) of the nonwoven material compared with the raw powder of the copolymer VDF-TeFE was estimated by equation:

$$
X_{c}(\%)=\left(1-H_{f s} / H_{f p}\right) \times 100 \%
$$

where $H_{f s}$ is the measured heat of fusion of the nonwoven material and $H_{f p}$ is the measured heat of fusion of the raw powder [29]. It should be noted that the magnitude of $H_{f}$ comprises of the heat of fusion of both paraelectric and ferroelectric phases above the Curie temperature.

\subsection{Spectroscopy analysis}

\subsubsection{FTIR spectroscopy}


Qualitative determination of residual organic solvents and the study of the chemical structure of the samples were performed using the Attenuated total reflectance (ATR) Fourier transform infrared (FTIR) spectroscopy, using Nicolet 6700 system (Thermo Scientific, USA) in the range of 400 to $2000 \mathrm{~cm}^{-1}$ with a resolution of $4 \mathrm{~cm}^{-1}$.

\subsubsection{Raman spectroscopy}

Study of the conformation of the polymer chains in the samples was carried out by Raman spectroscopy using Nicolet NXR9650 (Thermo Scientific, USA) using the wavelength of 1.06 $\mu \mathrm{m}$, the spectral range from 400 to $1400 \mathrm{~cm}^{-1}$ and the resolution of $4 \mathrm{~cm}^{-1}$.

\subsection{Gas chromatography}

Quantitative determination of residual acetone was carried out by gas chromatography using Hewlett-Packard 5890 Series II gas chromatograph equipped with a flame ionization detector and a $30 \mathrm{~m} \times 0.32 \mathrm{~mm}, 0.25 \mu \mathrm{m}$ capillary column (Agilent 123-7032). A sample weighing $0.100 \pm 0.001 \mathrm{~g}$ was placed in a $10 \mathrm{ml}$ volumetric flask and about $7 \mathrm{ml}$ of analytical grade cyclohexanone (BASF) was added. Then the flask was stoppered, placed in a shaking water bath at $60{ }^{\circ} \mathrm{C}$ and incubated until a homogeneous clear liquid was obtained. After complete dissolution of the sample the flask was cooled to room temperature, the volume was made up to $10 \mathrm{ml}$ with cyclohexanone and the solution was stirred.

A $0.5 \%$ by wt. acetone solution in cyclohexanone was used as the standard reference solution. $63.2 \mu 1$ of acetone (Merck, analytical grade) was micropipetted into a $10 \mathrm{ml}$ volumetric flask, then the volume was made up to $10 \mathrm{ml}$ with analytical grade cyclohexanone, and the solution was stirred. Five subsequent chromatograms of the reference solution and the solution being tested were recorded. The thermostat was set to $30{ }^{\circ} \mathrm{C}$ for $0-5 \mathrm{~min}$, then heated to $222{ }^{\circ} \mathrm{C}$ at 20 ${ }^{\circ} \mathrm{C} / \mathrm{min}$, and kept at $222{ }^{\circ} \mathrm{C}$ for $25 \mathrm{~min}$, the inlet temperature and the detector temperature were set to $250{ }^{\circ} \mathrm{C}$ and $222^{\circ} \mathrm{C}$ respectively. The pre-column pressure, hydrogen flow rate and air flow rate were $0.8 \mathrm{bar}, 20 \mathrm{ml} / \mathrm{min}$ and $200 \mathrm{ml} / \mathrm{min}$ respectively. Under these conditions retention times for acetone and cyclohexanone were about $2.4 \mathrm{~min}$ and 10.3 minutes respectively. In the chromatograms of the reference solution and the solution being tested the areas of the peak due to acetone were determined and the acetone concentration in the scaffolds ( $X_{c}, \% \mathrm{wt}$.) was calculated using the following equation:

$$
X_{c}=\frac{S \cdot C_{0}}{S_{0}}
$$


where $S$ and $S_{0}$ are the areas of the acetone peak on the chromatograms of the test and the reference solutions respectively, and $C_{0}(\% \mathrm{wt}$.) is the acetone content in the reference solution.

\subsection{Cytotoxicity study of the nonwoven material}

The toxicity of samples was investigated using toxicity analyser (AT-05, ZAO “MBK-INVEST”, Russia). Toxicity was evaluated by comparing mobility of the suspension culture of motile cells in the control solution to that in the test solution. Solution of $4 \mathrm{~g}$ of glucose (Sigma) and $1 \mathrm{~g}$ of Trisodium citrate (Sigma) in $100 \mathrm{~g}$ of distilled water ("Biolot", Russia) was used as the control solution. Test solutions were prepared by incubating the samples with dimensions $10 \times 10 \times 0.2$ $\mathrm{mm}$ each in $20 \mathrm{ml}$ of the control solution in thermostat for $24 \mathrm{~h}$ at $37 \pm 2{ }^{\circ} \mathrm{C}$. The suspension culture of motile cells was prepared by placing granules of liquid nitrogen cooled bovine semen into a test tube with $0.4 \mathrm{ml}$ of control solution that was preheated to $(40 \pm 1.5){ }^{\circ} \mathrm{C}$. After thawing, the content of all test tubes was thoroughly mixed together and yielded a stock solution of the culture of motile cells. For testing toxicity $0.1 \mathrm{ml}$ of the stock solution was placed with $20 \mathrm{ml}$ of the control and test solutions, which then transferred onto rectangular cells of $25 \mu$ l volume and $200 \mu \mathrm{m}$ thickness. The mobility of the sperm suspension was then measured at regular time intervals until mobility in all samples was negligible. Weighted average of the mobility $\left(t_{a v}\right.$, in arbitrary units) for each sample was calculated using equation:

$$
t_{a v}=\ln m_{1} \frac{\sum_{i}\left(m_{i} \cdot i\right)}{\sum_{i} m_{i}}
$$

where $m_{i}$ is the mobility value at the $i$-th time interval.

Toxicity index was then calculated using equation:

$$
I_{t}=\frac{t_{a v}^{t}}{t_{a v}^{c}} \times 100 \%
$$

where $t_{a v}^{t}, t_{a v}^{c}$ are weighted average of the mobility for the test and control samples. The sample was considered non-toxic if its toxicity index was in the range of 70-120 \% [30].

\subsection{Investigation of the nonwoven material influence on the morpho-functional status of human stromal cells}

In vitro biological response to the scaffolds was tested using the culture of human lung prenatal stromal cells (HLPSC), obtained from the Bank of Stem Cells Ltd (Tomsk, Russia). HLPSC are 
$\mathrm{CD}^{-}{ }^{-} \mathrm{CD} 44^{+}$adherent cells, maintaining diploid karyotype and oncological safety during ex vivo passages. Cells are free from viral (HIV, hepatitis, herpes etc.), bacterial (syphilis, mycoplasma, chlamydiae, etc.) and fungous agents. Original cell viability (before incubation) was determined in accordance with ISO 10993-5 by the counting non-stained cells in the test with $0.4 \%$ trypan blue and was determined to be $92 \%$.

Test samples with dimensions of $10 \times 10 \mathrm{~mm}$ were placed in the wells $\left(1.9 \mathrm{~cm}^{2}\right.$ area) of 24-well plastic plates (Corning, USA) and the cell suspension was added at a concentration of $5 \times 10^{4}$ viable karyocytes in $1 \mathrm{ml}$ of the culture medium. Cells were cultivated at $37{ }^{\circ} \mathrm{C}$ at $100 \%$ humidity and $5 \% \mathrm{CO}_{2}$ atmosphere.

The culture medium without osteogenic supplements was used with the following composition: $80 \%$ of the medium DMEM/F12 (Gibco, UK), $20 \%$ of fetal bovine serum (Sigma), $280 \mathrm{mg} / \mathrm{l}$ of L-glutamine (Sigma) and $50 \mathrm{mg} / \mathrm{l}$ of gentamicin (Invitrogen, UK).

The cell culture in the plastic wells (without adding the test samples) was used as the growth control. After 4 days of cultivation the scaffolds were removed. Parts of the plates were cultivated for up to 8-days to provide the control of the dynamics of cell growth. Supernatants (extracellular fluid) were separated from the cell cultures and collected into test tubes, then centrifuged at $500 \mathrm{~g}$ for $15 \mathrm{~min}$. The following markers of the functional state of HLPSC were measured in the extracellular fluid: the activities of alkaline phosphatase (ALP) and acid phosphatase (ACP), the concentrations of calcium (total and ionized) and inorganic phosphorus. Biochemical studies were performed according to the instructions of the manufacturer of the sets (Thermo Fisher Scientific Inc., Biochemical analyser Konelab 60 i, USA) using a standard colorimetric method.

After removal of the supernatant, adhered cells were air dried for 24 hours, fixed for $30 \mathrm{~s}$ in $40 \%$ formaldehyde vapor for cytochemical staining for ALP. ALP activity in the cells was determined by the Gomori’s diazocoupling technique using fast blue PP salt (Lachema, Czech Republic).

The results of cell staining were evaluated by computer morphometry using a program Image $\mathrm{J}$ 1.38 (National Institutes of Health, USA). The total number of fibroblast-like cells and the number of blue-stained ones were estimated in 10 digital images (a resolution of $300 \mathrm{dpi}$ ) on each group. The percent of ALP-stained fibroblast-like cells was counted. 


\subsection{Statistical data analysis}

The data were analysed using the methods of statistical description and statistical hypothesis testing available in the standard software package Statistica (version 6.0). The results were expressed as the mean (X), median (Me), $25 \%(\mathrm{Q} 1)$ and $75 \%$ (Q3) quartiles, the standard deviation (SD) and the error of the mean (m). For the analysis of the data the hypothesis of normal distribution (Kolmogorov-Smirnov test) was used. In the case of the normal distribution the statistical significance was assessed using the Student's $t$-test, in other cases non-parametric U-Mann-Whitney test $\left(\mathrm{P}_{\mathrm{U}}\right)$ was used. Differences were considered statistically significant at a significance level of $\mathrm{p}<0.05$.

\section{Results and discussion}

\subsection{The surface morphology, porosity and EDX}

The solution with $9 \%$ concentration of the copolymer of VDF-TeFE caused clogging of the spray nozzle, and we were unable to form the nonwoven material using this solution. Images of the surface morphology of the nonwoven material formed from the polymer solution with concentrations of 3 and $7 \%$ are shown in Fig. 2a and 2b, respectively.

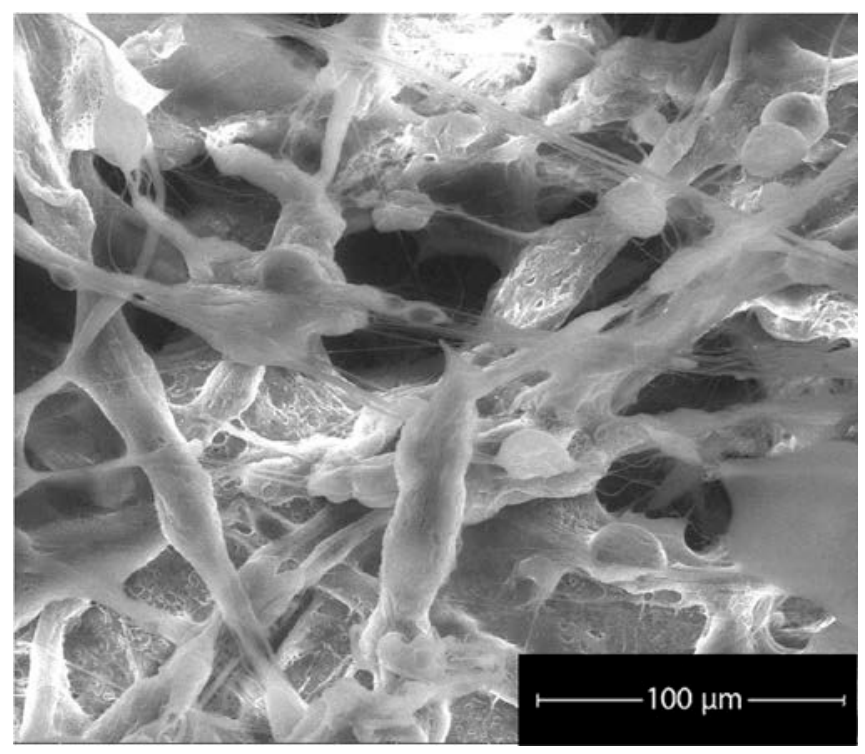

a

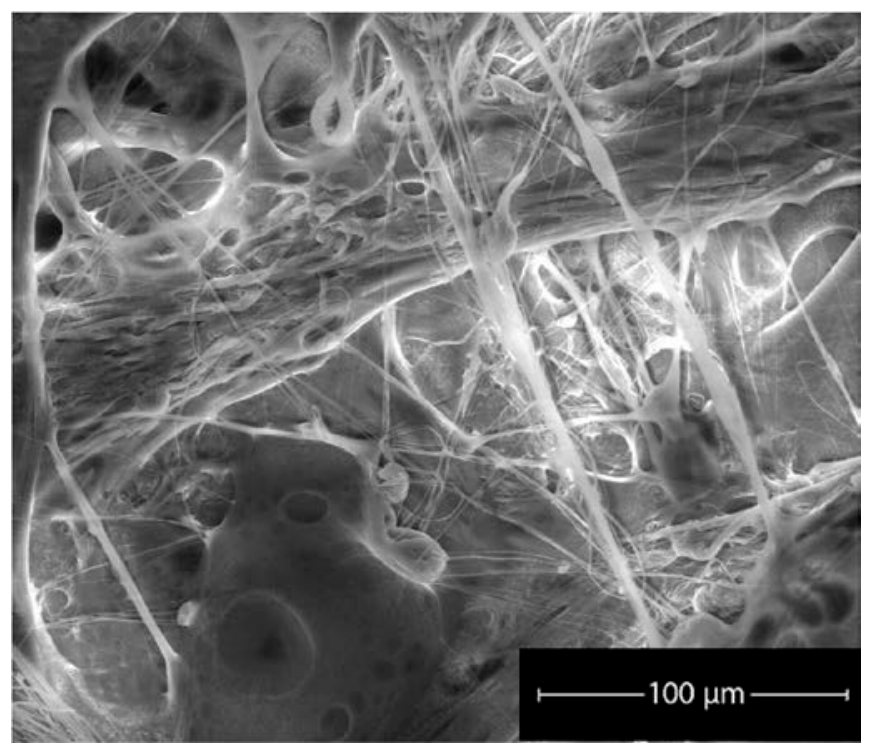

b

Fig. 2. SEM images of nonwoven materials formed from the polymer solution with concentrations of 3 $\%$ (a) and $7 \%$ (b).

The use of the polymer solution with the concentration of $3 \%$ leads to the nonwoven material to be formed as cigar-shaped elongated structures which are poorly bonded to each other (Fig. 2a). 
Such structure of the material is due to the fact that during the formation a significant proportion of the organic solvent has no time to evaporate along the path from the nozzle to the collector, thus reaching the collector and causing partial dissolution of the formed material. The nonwoven fabric formed from the polymer solution with the concentration of $7 \%$ was in the form of a film with some inclusions of thick fibres on its surface (Fig. 2b). Thus, our study confirms earlier results obtained by different research groups, indicating a narrow range of concentrations of polymer solutions that are suitable for the formation of nonwovens by SBS [25, 29, 31].

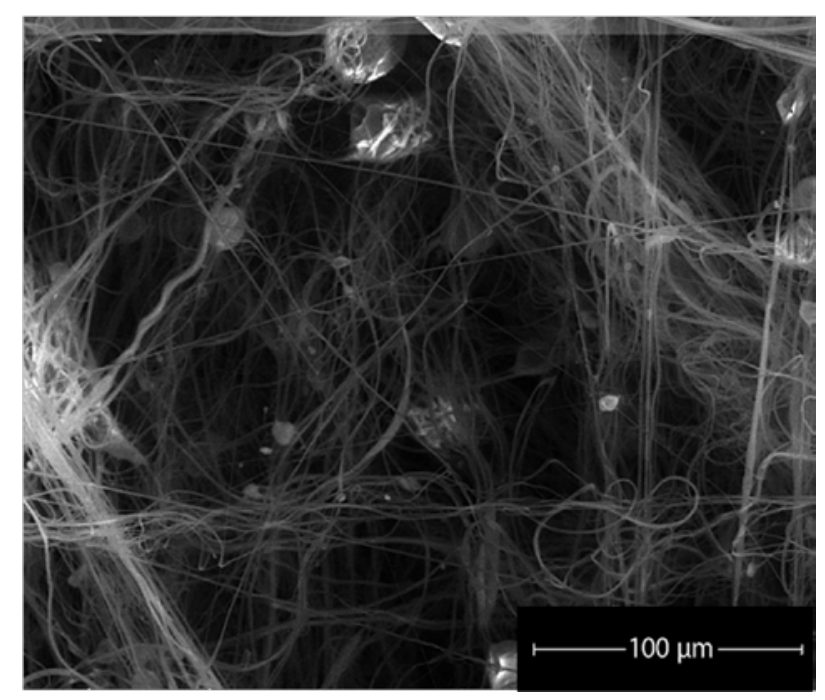

a

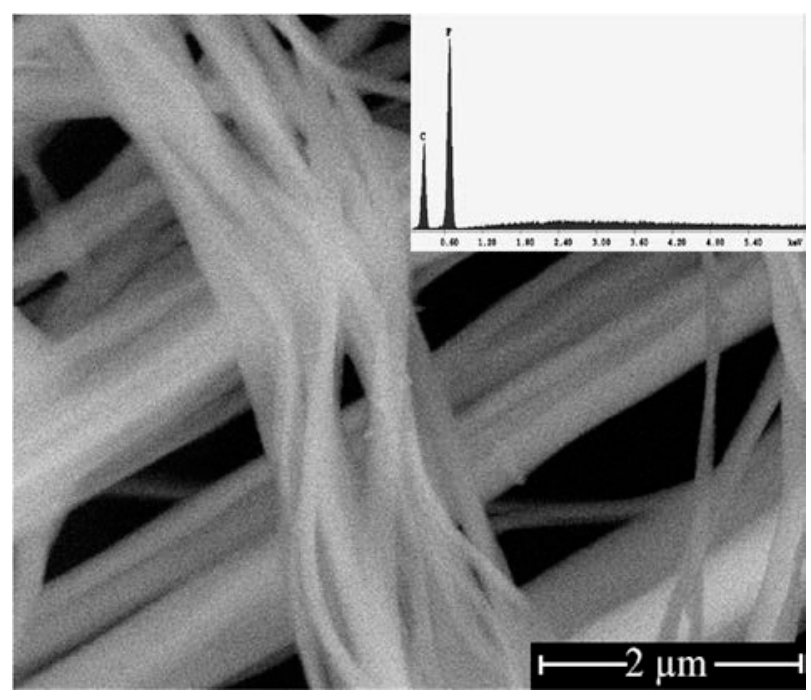

$\mathrm{b}$

Fig. 3. SEM images of the nonwoven material obtained from $5 \%$ solution of the polymer at low (a) and high (b) magnifications and its EDX spectra (b, insert).

Fig. 3 shows the morphology of the nonwoven material formed from the polymer solution with 5 \% concentration. Unlike nonwoven materials prepared by electrospinning, which are characterized by high uniformity of the fibres, nonwoven materials obtained by SBS from $5 \%$ solution of the copolymer VDF-TeFE have a complex spatial organization which can be divided into three dimensional levels: macro, micron and nano scales. The macro scale structures, with an average diameter of $36 \pm 5 \mu \mathrm{m}$ (Fig. 3a), are formed with micro fibres, with a diameter of $2.3 \pm 0.4 \mu \mathrm{m}$ (Fig. 3b), that are predominantly oriented along the macro scale structure's axes. The micro fibres are composed of nanofibres, with an average diameter of $170 \pm 30 \mathrm{~nm}$ that are bonded together and oriented along the micro fibres. The multi-level structure produces a developed relief of individual microfibres and material as a whole. Polymer droplets with an average diameter of $17 \pm 3 \mu \mathrm{m}$ are also present in the structure of the nonwoven material (see Fig. 3a). The porosity of the nonwoven material, calculated using equation (1), was $46 \pm 2 \%$. Thus, 
our studies suggest the fractal structure of the fabricated material. It should be noted that the structural units of the nonwoven material have a developed macro- and micro-relief, which should contribute to effective populating of the material by cells in vitro. This ability will also be helped by the high porosity of the material. In our opinion nonwoven materials formed from solutions with the concentration of 3 and $7 \%$ due to their morphological features are not of sufficient interest for biomedical applications, therefore we focused in this work on the study of the material derived from the $5 \%$ solution.

A typical EDX spectrum of the nonwoven material is shown in Fig. 3b (Insert). The peaks of carbon and fluorine, which are the basic elements of the polymer chain of the copolymer of tetrafluoroethylene with vinylidene fluoride, are present in the spectrum. The lack of oxygen peak in the spectrum suggests that the scaffold has no significant concentration of acetone that was used as a solvent in the preparation.

\subsection{Mechanical properties}

Typical tensile strain curves for samples of nonwoven material are shown in Fig. 4.

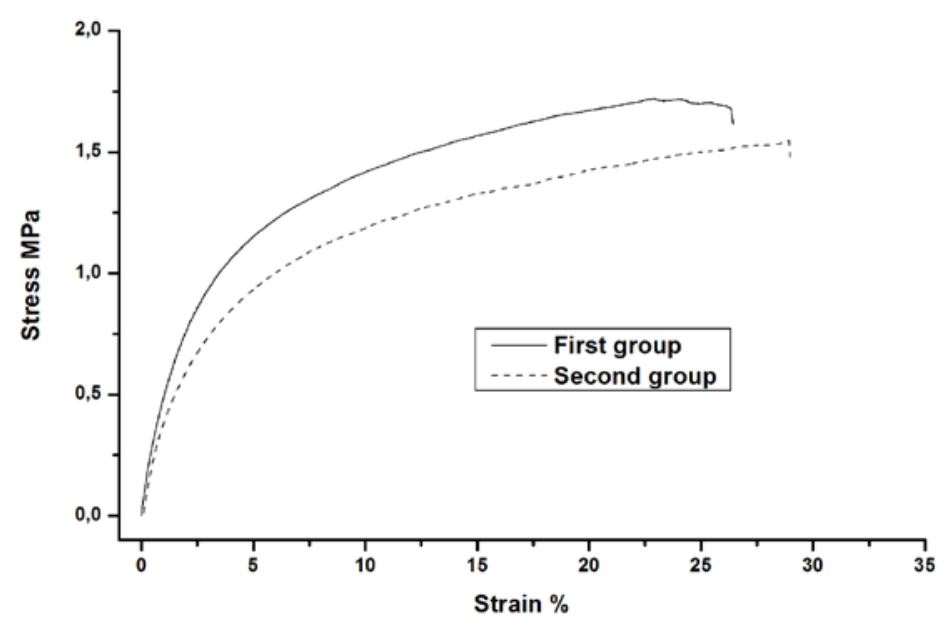

Fig. 4. Tensile strain curves for the samples.

Analysis of tensile strain dependency of the samples of nonwoven material shows that the elongations of samples of the first and second groups are $24 \pm 3$ and $28 \pm 8 \%$ respectively, on average about $15 \%$ difference. The tensile strength at maximum load, $1.62 \pm 0.31 \mathrm{MPa}$ and 1.48 $\pm 0.24 \mathrm{MPa}$ for the first and second groups respectively, are not significantly different. The 
modulus of elasticity of the samples of the first group (5.3 $\pm 0.2 \mathrm{MPa})$ are higher by about $16 \%$ than that of the second group ( $4.5 \pm 0.3 \mathrm{MPa})$.

Tensile strain dependencies demonstrate that the nonwoven material has anisotropic mechanical properties. Anisotropy of the mechanical properties of the material can be caused by a preferred orientation of macro bundles during the formation of the nonwoven material.

\subsection{Thermal analysis}

\subsubsection{TGA analysis}

Fig. 5 shows a typical TGA thermogram of copolymer powder VDF-TeFE (Fig. 5a) and the nonwoven material obtained by SBS method (Fig. 5b).

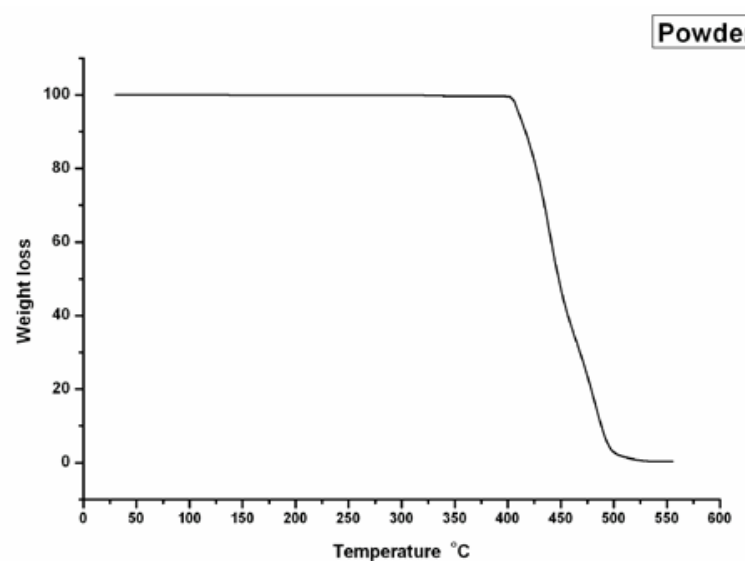

$\mathrm{a}$

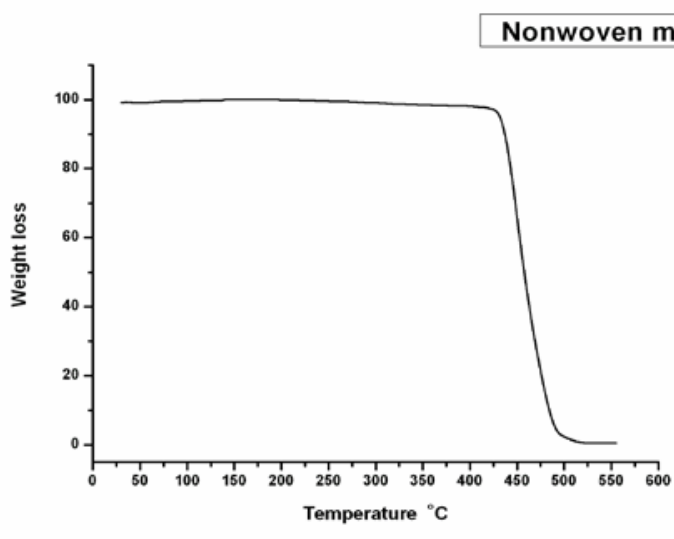

b

Fig. 5. TGA thermogram of the powder (a) and the nonwoven material (b).

The copolymer powder VDF-TeFE has high thermal stability in an oxidizing atmosphere and according to the thermogram of the powder (Fig. 5a) retains its mass until the onset of the thermal decomposition $\left(T_{\mathrm{A}}\right)$ at $400 \pm 3{ }^{\circ} \mathrm{C}$. The temperature of completion of the thermal decomposition $\left(T_{B}\right)$ is $490 \pm 3{ }^{\circ} \mathrm{C}$. The temperature range of the thermal decomposition process, for the selected parameters of heating, is about $90 \pm 3{ }^{\circ} \mathrm{C}$ and the temperature of halfdecomposition $\left(T_{\mathrm{C}}\right)$ is located near $441 \pm 3^{\circ} \mathrm{C}$.

The thermogram of the nonwoven material (Fig. 5b) demonstrates a weight increase on average of $0.7 \pm 0.2 \%$ compared to the initial mass in a temperature range of $30-143{ }^{\circ} \mathrm{C}$. At a temperature between $143-195{ }^{\circ} \mathrm{C}$ the weight of the nonwoven material is at a maximum and does not change up to the temperature of $195 \pm 3{ }^{\circ} \mathrm{C}$. At a temperature between $195-420{ }^{\circ} \mathrm{C}$ the weight of the 
nonwoven material is reduced by an average of $1.9 \pm 0.2 \%$, then at the temperature $T_{\mathrm{A}}=423 \pm 3$ ${ }^{\circ} \mathrm{C}$ begins the process of intensive thermal decomposition which ends at $T_{B}=490 \pm 3{ }^{\circ} \mathrm{C}$. Halfdecomposition temperature of the nonwoven material is $T_{\mathrm{C}}=455 \pm 3{ }^{\circ} \mathrm{C}$.

Minor weight fluctuations of the nonwoven material as compared to the raw powder in the process of thermal heating may be due to both the properties of the nonwoven material (high porosity, acetone residues and differences of the crystal structure), and the conditions of the study (heating rate, atmosphere) [32].

\subsubsection{DSC analysis}

Fig. 6 shows a typical DSC thermograms of the copolymer powder VDF-TeFE (Fig. 6a), and the nonwoven material obtained by the SBS method (Fig. 6b).

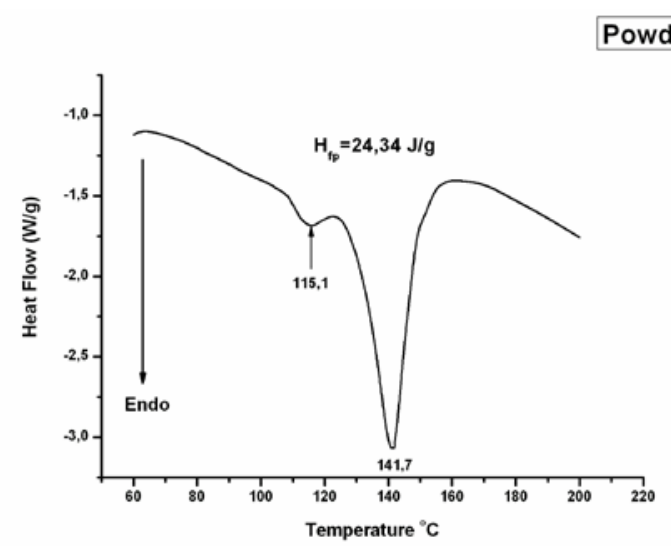

$\mathrm{a}$

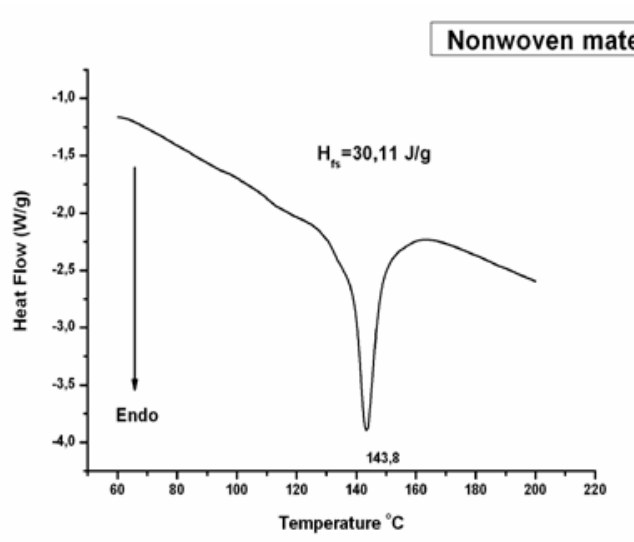

b

Fig. 6. DSC thermograms of the powder (a) and the nonwoven material (b).

The thermogram of the powder (Fig. 6a) has two separate endothermic peaks: the first at $115.2 \pm 0.2{ }^{\circ} \mathrm{C}$ and the second, much more intense, at $141.7 \pm 0.2^{\circ} \mathrm{C}$. The heat of fusion of the raw powder is $H_{f p}=24.24 \pm 0.15 \mathrm{~J} / \mathrm{g}$. The thermogram of the nonwoven material (Fig. 6b) has only one intense endothermic peak at $143.8 \pm 0.5^{\circ} \mathrm{C}$. The heat of fusion of the nonwoven material is $H_{f s}=30.11 \pm 0.15 \mathrm{~J} / \mathrm{g}$. The increase in the degree of crystallinity of the nonwoven material compared to the untreated powder, calculated by equation (3), was $23.7 \pm 0.6 \%$.

DSC analysis demonstrated the restructuring of the crystal structure of VDF-TeFE during fabrication of the nonwoven material, as evidenced by differences in thermograms of samples to that of the initial copolymer powder. The first endothermic peak in the thermograms detectable in the untreated powder of copolymer VDF-TeFE obtained from the solution is due to the energy 
required for adjustment of the crystal structure of the polymer material at the transition from the ferroelectric to paraelectric state. Intense endothermic peak at temperature of about $140{ }^{\circ} \mathrm{C}$ corresponds to the melting of copolymer VDF-TeFE [33]. Formation of ordered ferroelectric $\beta$ phase leads to overlapping of the endothermic peak corresponding to the Curie transition and the endothermic peak corresponding to the melting of the copolymer VDF-TeFE, with simultaneous increase of the heat of fusion of the nonwoven material. This phenomenon for copolymer VDFTeFE was first demonstrated by Murata and Koizumi [34], and was explained by significant residual polarization after exposure of the polymer to electric fields of high intensity. Thus, we can assume that the tensile forces exerted by the turbulent gas stream are similar to an electric field of high intensity, thereby causing polymer recrystallization into a highly ordered ferroelectric $\beta$ phase.

\subsection{X-ray diffraction}

Fig. 7 shows diffractograms of the samples. On the VDF-TeFE powder diffractogram (Fig. 7a) a number of reflexes are present: the most intense interchain reflex at an angle of $19.6^{\circ}$ corresponds to the reflection from the $(110,200)$ plane of the ferroelectric $\beta$ phase [35], a weak intra-molecular diffuse reflex near the angle of $35.5^{\circ}$ corresponds to the reflection from the (001) plane of $\beta$ ferroelectric phase and reflex near $40.5^{\circ}$ corresponds to the reflection from the plane $(201,111)$ of the ferroelectric phase $\beta$. The diffractogram of the nonwoven material (Fig. $7 \mathrm{~b}$ ) only has one interchain intense reflex corresponding to the reflection from the $(110,200)$ plane of the ferroelectric $\beta$ phase. Reflexs at angles $35.5^{\circ}$ and $40.5^{\circ}$ that correspond to reflection from the $(001)$ and $(201,111)$ planes of the ferroelectric $\beta$ phase are not detected. Data on the degree of crystallinity and an average crystal size of the samples are shown in Table 1.

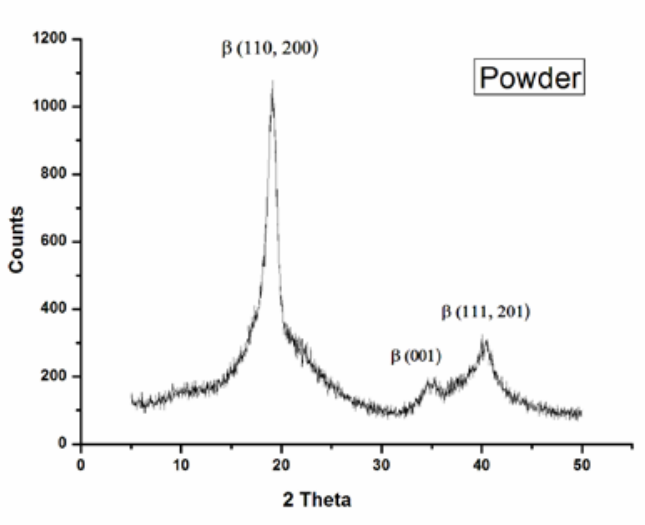

$\mathrm{a}$

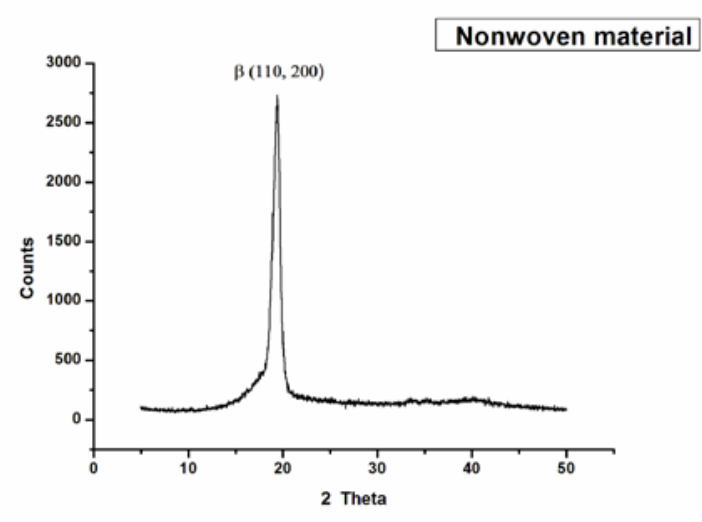

b

Fig. 7. XRD of the powder (a) and the nonwoven material (b). 
Table 1. Degree of crystallinity and crystal size.

\begin{tabular}{|l|c|c|c|c|}
\hline \multicolumn{1}{|c|}{ Sample } & \multirow{2}{*}{$\begin{array}{c}\text { Degree of } \\
\text { crystallinity (\%) }\end{array}$} & \multicolumn{3}{|c|}{ Crystal size (nm) } \\
\cline { 3 - 5 } & & $l_{001}$ & $l_{201,111}$ & $l_{110,200}$ \\
\hline Powder & $25 \pm 4$ & $2.2 \pm 0.3$ & $1.8 \pm 0.4$ & $3.8 \pm 0.3$ \\
\hline $\begin{array}{l}\text { Nonwoven } \\
\text { material }\end{array}$ & $48 \pm 3$ & N/A & N/A & $8.2 \pm 0.2$ \\
\hline
\end{tabular}

XRD studies supported the hypothesis of restructuring of the crystal structure of VDF-TeFE polymer during formation of the nonwoven material. The raw powder copolymer VDF-TeFE distinct intramolecular reflex (001) of $2 \theta=35.5^{\circ}$ indicates the presence of a polar crystals in the direction of the chain axis and its reduction in intensity for the nonwoven material indicates that the polymer crystals in the process of forming the material take the form of thin plates that decrease size in the direction of the chain axis. The process of forming the nonwoven material from the polymer solution under the effect of significant tensile forces from the turbulent flow of gas contributes to increase in both the size and proportion of ferroelectric crystals oriented in the direction perpendicular to the chain axis. This is confirmed by a significant decrease in the halfwidth interchain reflex (110 200) of $2 \theta=19.6^{\circ}$, as well as increase in the degree of crystallinity of the nonwoven material compared to the raw powder [36-37].

\subsection{FTIR spectroscopy}

Fig. 8 shows FTIR spectra for the samples.

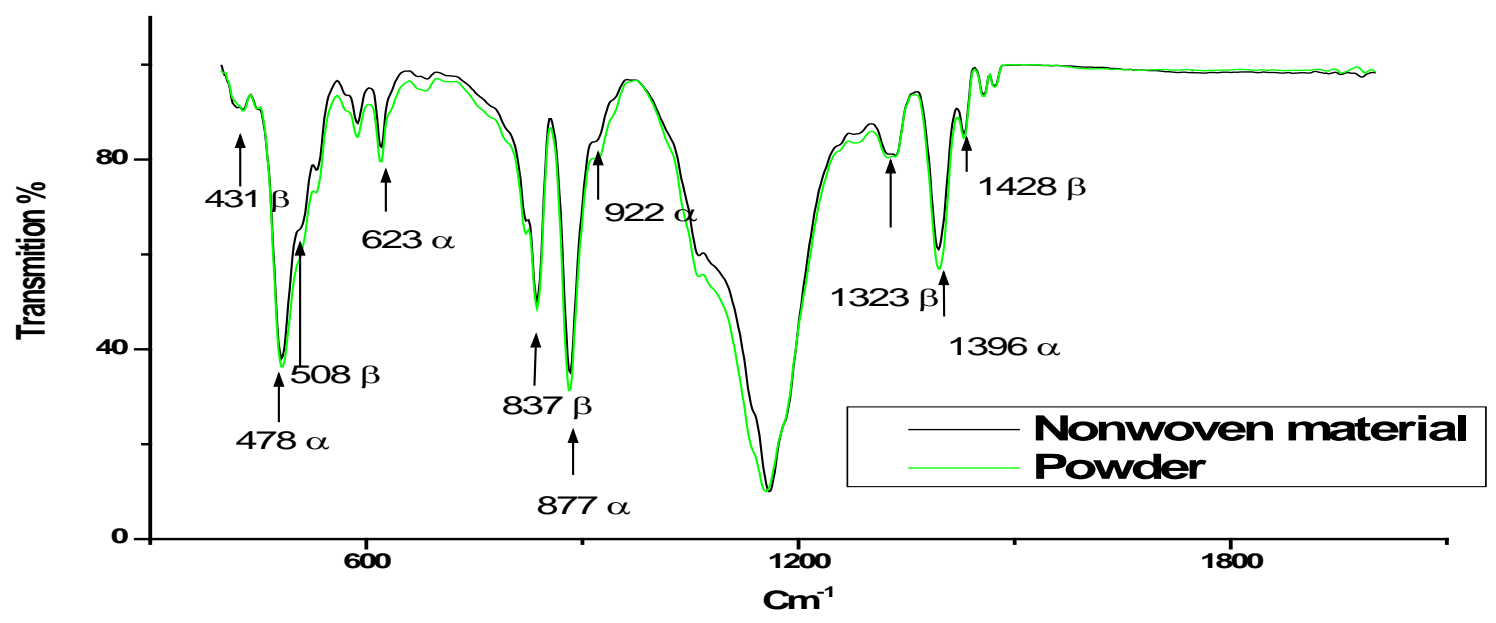

Fig. 8. FTIR spectra of samples. 
The spectra have several main absorption bands corresponding to the paraelectric $\alpha$ phase: the most intense bands are observed at frequencies of $1396 \mathrm{~cm}^{-1}\left(\mathrm{CH}_{2}\right.$ wagging), $877 \mathrm{~cm}^{-1}$ (-CH2 rocking), $478 \mathrm{~cm}^{-1}$ (-CH2 rocking and skeletal bending), $922 \mathrm{~cm}^{-1}$ (-CH2 rocking) and $623 \mathrm{~cm}^{-1}$ are assigned to the vibrational modes characteristic of the TFE sequence or the boundary between VDF and TFE segments. Also evident in the spectra are several major absorption bands corresponding to the ferroelectric $\beta$-phase $837 \mathrm{~cm}^{-1}$ (-CH2 groups collectively and symmetrically moving in-plane and perpendicular to the polymer chain axis), $1323 \mathrm{~cm}^{-1}$ ( $\mathrm{CH}$ rocking), 1428 $\mathrm{cm}^{-1}$ (CH2 bending), $431 \mathrm{~cm}^{-1}$ and $508 \mathrm{~cm}^{-1}$ (CC skeletal bending) [38-40]. FTIR studies also supported the restructuring of the crystal structure of the nonwoven material that leads to a highly ordered ferroelectric $\beta$ phase. This is confirmed by an increase in the intensity of the absorption bands in the spectra of the nonwoven material (compared with the IR spectrum of the raw powder) of 431, 837 and $1428 \mathrm{~cm}^{-1}$, as well as the appearance of a shoulder at $508 \mathrm{~cm}^{-1}$, which corresponds to the ferroelectric $\beta$ phase. At the same time the intensity of bands corresponding to a paraelectric $\alpha$ phase of 478, 877, 623, 1398 and $922 \mathrm{~cm}^{-1}$ decreases. The increase in the intensity of the absorption bands corresponding to the $\beta$ phase, and the decrease in the intensity of the bands corresponding to $\alpha$ phase in the films of the copolymer VDF-TeFE was noted in [41]. It is worth noting the absence in FTIR spectra of the absorption band at $1714 \mathrm{~cm}^{-1}$ corresponding to the carbonyl group of acetone, used as the process solvent for the production of the nonwoven material.

\subsection{Raman spectroscopy}

Fig. 9 shows Raman spectra for the samples.

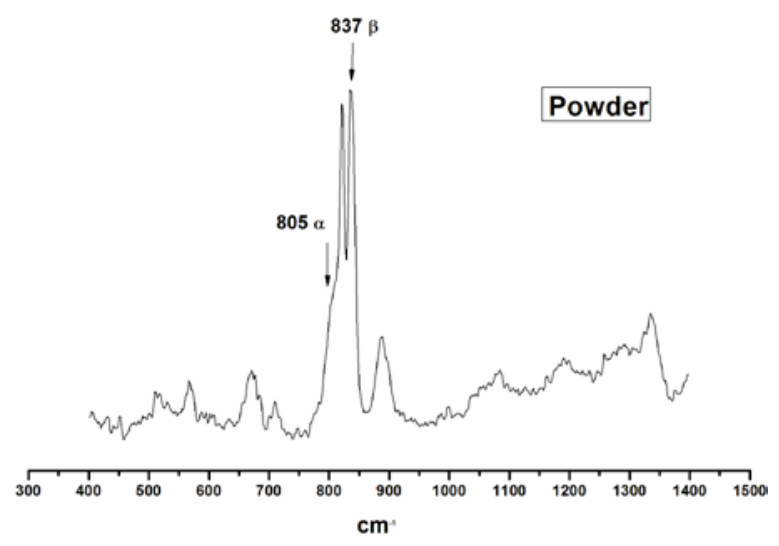

a

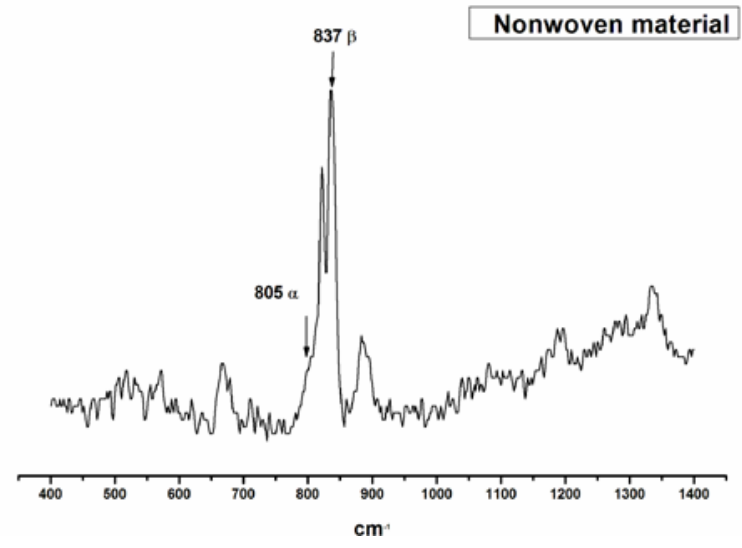

$\mathrm{b}$

Fig. 9. Raman spectra of the powder (a) and the nonwoven material (b). 
The Raman spectra of the samples have major bands that correspond to the conformation of the polymer chains. The band at $837 \mathrm{~cm}^{-1}$ (assigned to the vibrational modes characteristic of the TFE sequence or the boundary between VDF and TFE segments) corresponds to the $\beta$ phase of the ferroelectric. Shoulder at $805 \mathrm{~cm}^{-1}$ is due to the conformation of the polymer chains in the gauche form and corresponds to paraelectric $\alpha$ phase [41]. This result was confirmed by the Raman spectra, as a significant reduction in intensity of the shoulder at $805 \mathrm{~cm}^{-1}$ and an increase in the $837 \mathrm{~cm}^{-1}$ band shows an increase of the polymer crystals with the trans conformation, which corresponds to the ferroelectric $\beta$ phase [42-43].

\subsection{Gas chromatography}

An important step in developing highly porous materials using SBS method is the choice of an organic solvent. The basic requirements for the organic solvent used in the method are the low evaporation temperature and the minimum possible toxicity, therefore acetone was selected as the solvent for the production of the material. The GC study of the residual acetone in the samples yielded residual acetone concentration in the nonwoven material of $0.016 \pm 0.006 \%$ (wt.) which is much less than the allowable content of $0.5 \%$ (wt.). Studies carried out by other methods: EDX, FTIR, TGA also demonstrate that the amount of acetone is small. It is clear therefore that the selected method of vacuum distillation of the solvent was sufficient to remove the residual acetone from the nonwoven material.

\subsection{Cytotoxicity study of the nonwoven material}

The results of cytotoxicity studies of the powder and the nonwoven material yielded the toxicity index of $93 \pm 12$ and $91 \pm 14$ which is not significantly different and both within the acceptable range of 70 to $120 \%$. It can be concluded therefore that that samples have no cytotoxicity.

\subsection{Investigation of the nonwoven material influence on the morpho-functional status of human stromal cells}

The mediated effect of the nonwoven material on the cell culture was studied according to ISO 10993-5.

The results of in vitro biological testing on day 4 showed that on the plastic surface of the wells of culture plate the cells were hardly detectable under the nonwoven material (Fig. 10a). The presence of the nonwoven material in cell culture for 4 days had almost no effect on the number of fibroblast-like cells that are stained positive for alkaline phosphatase. Biochemical parameters had not changed in interstitial fluid (Table 2). 


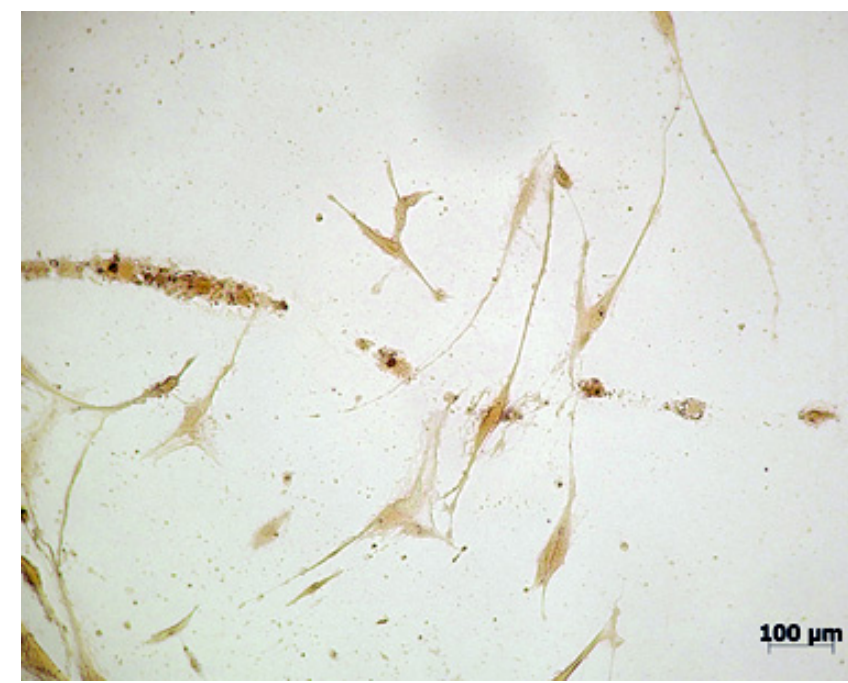

a

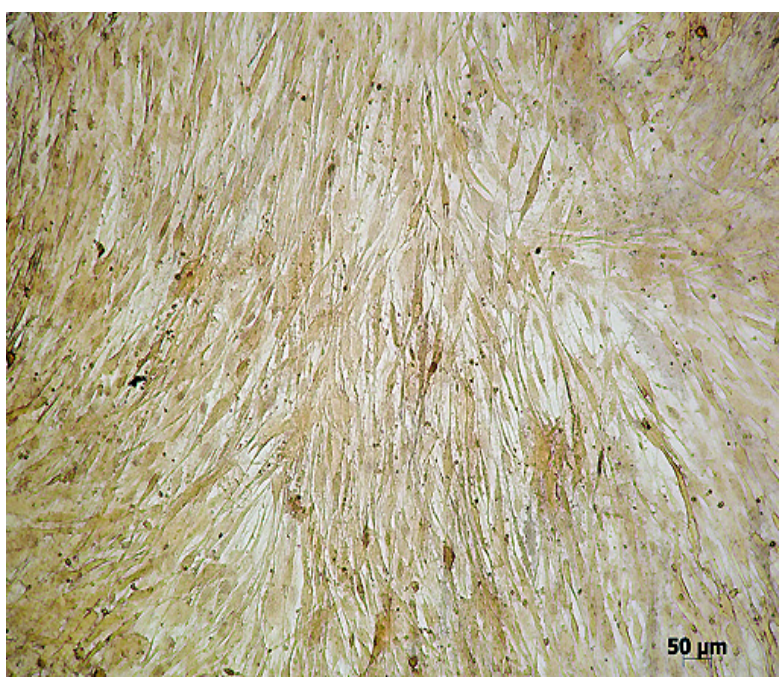

b

Fig. 10. State of the fibroblast-like stromal cells on the plastic surface under the scaffolds on the 4-th (a) and 8-th (b) day of cultivation. Cells are stained for alkaline phosphatase.

By the 8-th day the formation of the cell monolayer was obvious (Fig. 10b), not only in the control group, but also around the nonwoven material and beneath it.

Table 2. Morpho-functional indicators of 4-day culture of human lung prenatal stromal cells in the presence of the nonwoven material.

\begin{tabular}{|c|c|c|c|c|c|c|c|}
\hline \multirow{2}{*}{$\begin{array}{l}\text { Gro } \\
\text { up } \\
\text { No }\end{array}$} & \multirow{2}{*}{$\begin{array}{l}\text { Type of the } \\
\text { group, } n=3\end{array}$} & \multicolumn{5}{|c|}{$\begin{array}{l}\text { Biochemical parameters in the extracellular fluid, } \\
\text { Median (Q1-Q3) }\end{array}$} & \multirow{2}{*}{$\begin{array}{l}\text { \% ALP- } \\
\text { positive } \\
\text { cells on } \\
\text { the plastic } \\
\text { around the } \\
\text { scaffolds } \\
\mathrm{X} \pm \mathrm{SD} \text {, } \\
\mathrm{n} 1=10\end{array}$} \\
\hline & & $\begin{array}{l}\text { Ca total, } \\
\mathrm{mM}\end{array}$ & $\begin{array}{l}\mathrm{Ca}^{2+} \\
\mathrm{mM}\end{array}$ & $\begin{array}{l}\text { P inorganic, } \\
\mathrm{mM}\end{array}$ & $\begin{array}{l}\text { ACP, } \\
\text { unit/l }\end{array}$ & $\begin{array}{l}\text { ALP, } \\
\text { unit/l }\end{array}$ & \\
\hline 1 & $\begin{array}{l}\text { Control group } \\
\text { (cells on } \\
\text { plastic without } \\
\text { the nonwoven } \\
\text { material) }\end{array}$ & $\begin{array}{c}1.46 \\
(1.41-1.50)\end{array}$ & $\begin{array}{c}0.95 \\
(0.93-0.99)\end{array}$ & $\begin{array}{c}1.01 \\
(0.95-1.05)\end{array}$ & $\begin{array}{c}0.6 \\
(0.5-0.66)\end{array}$ & $\begin{array}{c}63 \\
(58-64)\end{array}$ & $0.30 \pm 0.84$ \\
\hline 2 & $\begin{array}{l}\text { Cells with the } \\
\text { nonwoven } \\
\text { material }\end{array}$ & $\begin{array}{c}1.38 \\
(1.35-1.48)\end{array}$ & $\begin{array}{c}1.02 \\
(0.94-1.04)\end{array}$ & $\begin{array}{c}0.96 \\
(0.86-0.97)\end{array}$ & $\begin{array}{c}0.4 \\
(0.3-0.4)^{*} \\
\mathrm{P} 1<0.05\end{array}$ & $\begin{array}{c}53 \\
(52-67)\end{array}$ & $0.44 \pm 1.07$ \\
\hline 3 & $\begin{array}{l}\text { Nonwoven } \\
\text { material in } \\
\text { medium } \\
\text { without cells }\end{array}$ & $\begin{array}{c}1.51 \\
(1.49-1.53)\end{array}$ & $\begin{array}{c}0.93 \\
(0.9-0.95)\end{array}$ & $\begin{array}{c}0.97 \\
(0.91-1.00)\end{array}$ & $\begin{array}{c}0.4 \\
(0.32- \\
0.41)\end{array}$ & $\begin{array}{c}56 \\
(49-61)\end{array}$ & - \\
\hline
\end{tabular}


Note: $\mathrm{n}$ - the number of the samples (wells on the plate) in each group; $\mathrm{n} 1$ - the number of digital videos to count ALP-stained cells in each group; ALP - alkaline phosphatase; ACP - acid phosphatase; * - statistically significant differences from one group according to Mann-Whitney U-test.

Levels of calcium, phosphate groups and ALP activity varied in the range of the control values (Table 2). The only exception was reduction (by $33 \%, \mathrm{P}_{\mathrm{U}}<0.05$ ) of the activity of acid phosphatase in comparison with the control. However, the same value $(0.4 \mathrm{U} / \mathrm{ml})$ was found for the scaffolds without cells. Apparently, this change was due to the reaction of the enzyme in the culture medium to the sterilizing agent remaining in the nonwoven material. Cytotoxicity studies of the nonwoven material using the culture of motile cells showed no toxicity. This further confirms that the proposed process of vacuum treatment of the nonwoven material is sufficient for the removal of acetone.

The in vitro study of the nonwoven material on morpho-functional status of the HLPSC has shown an exponential growth of the culture of human fibroblast-like stromal cells until the formation of the cell monolayer by the 8-th day. Possible degradation products of the nonwoven material and the factors secreted by cells interacting with it do not have an appreciable effect on the morphology and dynamics of cell growth compared with the control (cell culture without the nonwoven material).

A small amount of HLPSC-under the nonwoven material on day 4 of the cultivation can be caused by a significant negative surface potential inherent to the ferroelectric copolymers VDFTeFE [45]. The stimulating effect of ferroelectric phase $\beta$ on the attachment and proliferation of cell culture to VDF polymer surface was shown in [46].

The presence of the nonwoven material in cell culture for 4 days had almost no effect on the number of ALP-stained fibroblast-like cells and biochemical parameters did not change in the extracellular fluid (Table 2). Levels of calcium, phosphate groups, and the ALP activity ranged within the control group (without the scaffolds) values.

The results demonstrated that residual acetone and the possible degradation products of the scaffolds and factors secreted by cells interacting with them do not seem to have much effect on 
the morpho-functional status and dynamics of cell growth compared with the control group (cells cultured without the scaffolds).

\section{Conclusion}

This work demonstrated that SBS method without high voltage equipment can be used as an alternative to the electrospinning method to produce ferroelectric nonwoven polymeric scaffolds based on a copolymer of VDF-TeFE. The optimum morphology of the nonwoven scaffolds for medical applications with fractal structure and anisotropic mechanical properties is achieved by using $5 \%$ solution of the copolymer. Our experimental studies demonstrated that the fabricated nonwoven material exhibit ferroelectric properties and have complex spatial structure. The content of residual organic acetone in the nonwoven material was below $0.5 \%$, which combined with the lack of significant effect of the nonwoven materials on the morphology and function of HLPSC in vitro demonstrates their potential biological inertness. Therefore, the nonwoven scaffolds appear to be a convenient basis for constructing delivery systems for cells, drugs and biological molecules in bioengineering of soft tissues. However, in accordance with the ISO 10993-5, depending on the possible uses of the developed nonwoven materials, a number of additional tests, which take into account the specificity and scope of application, are required.

\section{Acknowledgments}

The work was performed with the support of Federal Target Program (state contract № 14.512.11.0012), RFBR (project № 13-08-98052 р_сибирь_a), state order (project № 7.1084.2011).

\section{References}

1. F. Rüfe, J. Eisenack, A. Klettner, R. Zeuner, J. Hillenkamp, G. Westphal, J. Roider, B. Nölle. Am. J. of Ophthalmol. 2011;151:703 - 713.

2. V.V. Soroka, V.E. Dyakov, T.N. Suborova. Angiol. and Vasc. Surg. 1997;1:79 - 82.

3. M. Voegele-Kadletz, E. Wolner. Mater. Sci. and Eng. 2011;31:1195 - 1200.

4. U. Klinge, K. Junge, V.Schumpelick, B. Klosterhalfen, A.P. Öttinger. Biomater. 2002;23:3487 - 3493.

5. G. Mania, M.D. Feldman, D. Patel, C.M. Agrawal. Biomater. 2007;28:1689 - 1710.

6. G. Jin, Q. Yao, S. Zhang, L. Zhanga. Mater. Sci. and Eng. 2008;28:1480 - 1488.

7. F.J. Correa, B.S. O. Rogeroa, A.A Coutoa., R.F. Costa Marques, A.A. Ribeiro, J.S. Campos. Mater. Res. 2007;10:247 - 251. 
8. A.M. Aronov, E.N. Bol’basov, V.V. Guzeev, M.V. Dvornichenko, S.I. Tverdokhlebov, I.A. Khlusov. Biomed. Eng. 2010;3:108 - 113.

9. J.S.C. Campos, A.A. Ribeiro, C.X. Cardoso. Mater. Sci. and Eng. 2007;136:123 - 128.

10. M. Yousefpour, A. Afshar, J. Chen, X. Zhang. Mater. Sci. and Eng. 2007;27:1482 1486.

11. J.C. Hicks, T.E. Jones, J.C. Logan. J. of Appl. Phys. 1978;49:6092 - 6096.

12. J. Watanabe, K. Imai, I. Uematsu. Macromol. 1986;19:1491 - 1494.

13. F.R. Valentini. Biomater. 1992;13:183 - 190.

14. F.R. Valentini, T.G. Vargo, J.A. Gardella, P. Aebischer. J. of Biomater. Sci., Polym. Edition 1994;5(1-2):13 - 36.

15. Y.-S. Lee, G. Collins, T.L. Arinzeh. Acta Biomaterialia 2011;7:3877-3886.

16. N. Weber, Y.-S. Lee, S. Shanmugasundaram, M. Jaffe, T.L. Arinzeh. Acta Biomaterialia 2010;6:3550 - 3556.

17. Y. Dzenis. Sci. 2004;304:1917 - 1919.

18. J. Lannutti D. Reneker, T. Ma, D. Tomasko, D. Farson. Mater. Sci. and Eng.: C 2007;27(3):504 - 509.

19. S. Agarwal, J.H. Wendorff, A. Greiner Polym. 2008;49:5603 - 5621.

20. S. Ramakrishna, K. Fujihara, W. Teo, T. Lim, Z. Ma. An introduction to Electrospinning and Nanofibers. Singapore: World Scientific Publishing, 2005.

21. E.S. Medeiros, G.M. Glenn, A.P. Klamczynski, W.J. Orts, L.H.C. Mattoso J. of Appl. Polym. Sci. 2009;113 2322 - 2330.

22. L.F. Zhang, P. Kopperstad, M. West, N. Hedin, H. Fong. J. of Appl. Polym. Sci. 2009;114:3479 - 3486 .

23. X. Zhuang, L. Shi, K. Jia, B. Cheng, W. Kang J. of Membr. Sc. 2013;429:66 - 70.

24. X. Zhuang, X. Yang, L. Shi, B. Cheng, K. Guan, W. Kang. Carbohydr. Polym. 2012;90:982 - 987.

25. W. Tutak, S. Sarkar, S. Lin-Gibson, T.M. Farooque, G.J.D. Wang, J. Kohn, D. Bolikal, C.G.Jr. Simon. Biomater. 2013;34:2389 - 2398.

26. J.B. Lando, W.W. Doll. J. of Macromol. Sci.; Part B: Physics 1968;B2:205 - 218.

27. Yu.A. Panshin, S.G. Malkevich, Ts.S. Dunaevskaya. Ftoroplasts. St. Petersburg: Chimia, 1978.

28. K. Tashiro, M. Kobayashi. Ph. Transit. 1989;18:213 - 246.

29. J. E. Oliveira, E. A. Moraes, R. G. F. Costa, S. Afonso, L. Mattoso, W. J. Orts, E. S. Medeiros. J. of Appl. Polym. Sci. 2011; 122, 3396-3405. 
30. A.P. Eskov, R.I. Kayumov, A.E. Toxicol. Lett. 2012;211S.

31. S. Srinivasan, S. S. Chhatre, J. M. Mabry , R. E. Cohen , G. H. McKinley. Polym. 2011;52 ; 3209- 3218.

32. V. Sencadas, S. Lanceros-Merndez, F. Mano. J. of Non-Cryst. Solids 2006;352:5376 5381.

33. A.J. Lovinger, G.E. Johnson, H.E. Bair, E.W. Anderson. J. of Appl. Phys. 1984;56:2412 $-2418$.

34. Y. Murata, N. Koizumi. Ferroelectr. 1989;92:47 - 54.

35. A.J. Lovinger. Macromol. 1983;16(9):1529 - 1534.

36. V.V. Kochervinskii, N.V. Kozlova, A.Y. Khnykov, M.A. Shcherbina, S.N. Sulyanov, K.A. Dembo . J. of Appl. Polym. Sci. 2010;116:695 - 707

37. A.J. Lovinger, D.D. Davis, R.E. Cais, J.M. Kometani. Macromol. I986;19(5):1491 1494.

38. K. Tashiro, H. Kaito, M. Kobayashi. Polym. 1992;33(14):2929 - 2933.

39. Z-Y. Wang K-H. Su, H-Q. Fan, Z-Y. Wen Polym. 2007;48:7145 - 7155.

40. K. Tashiro, Y. Abe, M. Kobayashi. Ferroelectr. 1995;171(1):281 - 297.

41. K. Tashiro, H. Kaito, M. Kobayashi. Polym 1992;33(14):2915 - 2928.

42. J. Green, J.F. Rabolt Macromol 1987;20:457 - 459.

43. K. Tashiro, M. Kobayashi. Polym. 1988; 29:426 - 436.

44. European pharmacopoeia 5.05 .4 residual solvents

45. S.I. Tverdokhlebov, E.N. Bolbasov, E.V. Shesterikov, A.I. Malchikhina, V.A. Novikov, Y.G. Anissimov. Appl. Surf. Sci. 2012;263:187 - 194.

46. C. Ribeiro, J.A. Panadero, V. Sencadas, S. Lanceros-Méndez, M.N. Tamaň, D. Moratal, M. Salmern-Sánchez, J.L. Gŏmez Ribelles Biomed Mater 2012;7: 035004. 